\title{
Los actos cívico-religiosos en las entidades locales: propuesta de un Proyecto de Reglamento para la festividad de San Antonio Abad de Trigueros (Huelva).
}

Civic-religious acts in local entities: proposal for a Regulation Project for the festivity of San Antonio Abad de Trigueros (Huelva)

\author{
Marcos del Toro Dominguez ${ }^{1}$ \\ Universidad de Sevilla \\ marcosdeltorod@gmail.com \\ Marta Pulido Polo ${ }^{2}$ \\ Universidad de Sevilla \\ martapulido@us.es
}

Recepción: 20/12/2018 Revisión: 04/01/2019 Aceptación: 13/02/2019 Publicación: 01/06/2019

\section{Resumen}

En este trabajo se analiza el caso de las fiestas patronales en honor a San Antonio Abad, que se dan en Trigueros, una localidad andaluza perteneciente a la provincia de Huelva. En estos festejos confluyen personalidades y autoridades civiles y religiosas cuya ordenación ceremonial corresponde con la tradición histórica de la celebración. A través de una metodología cuanticualitativa, este trabajo analiza desde una perspectiva diacrónica las precedencias en las diferentes secuencias de la ceremonia y concluye con la sistematización de las secuencias principales: el Traslado y la procesión de Tercia.

Palabras clave: ceremonial, protocolo local, fiestas populares, reglamentos.

\section{Abstract}

\footnotetext{
${ }^{1}$ Universidad De Sevilla

${ }^{2}$ Profesora Departamento Comunicación Audiovisual Y Publicidad Universidad De Sevilla
} 
This paper analyzes the case of the patron saint festivities in honor of San Antonio Abad, which take place in Trigueros, an Andalusian town belonging to the province of Huelva. These celebrations bring together personalities and civil and religious authorities whose ceremonial arrangement corresponds with the historical tradition of the celebration. Through a quantumquantitative methodology, this work analyzes from a diachronic perspective the precedences in the different sequences of the ceremony and concludes with the systematization of the main sequences: the Transfer and the procession of Tercia.

Keywords: ceremonial, local protocol, popular festivals, regulations.

\section{Sumario}

1. Introducción y objetivo

2. Metodología

3. El servicio de protocolo en las instituciones locales

4. Resultados

5. Conclusiones

6. Bibliografía

\section{INTRODUCCIÓN Y OBJETIVOS}

Desde el principio de los tiempos, el ser humano se ha valido de la religión para dar respuesta a diversas preguntas existenciales. La forma de comunicación con los dioses siempre se ha hecho a través de diversas ceremonias, rituales y fiestas, que han ido desde el sacrificio humano hasta la procesión una imagen. Para Navarro (1996:320):

Los procesos rituales festivos son especialmente reveladores de la realidad social, tanto por lo que reflejan como por lo que ocultan o niegan de ella. [...] Las fiestas constituyen, así, un lenguaje sobre la realidad y poseen un código comunicativo y un campo de significaciones sin acceder a los cuales captaríamos de ella, todo lo más, sus aspectos sensoriales, sin llegar a entender sus significados, que, por otra parte, pueden ser múltiples, como es normal por la naturaleza polisémica de todo mensaje simbólico.

Esta comunicación simbólica de lo divino con lo humano se resuelve a través del rito y la ceremonia y concluye en la popularización de determinadas festividades que, si bien tienen un origen religioso, vienen en derivar en marcadores claramente culturales que incluso identifican las tradiciones de determinadas localidades, como sucede por ejemplo con la Semana Santa de Sevilla, por ejemplo. Para Ruiz (2002: 310), además, la religiosidad popular 
pierde ya en el siglo XX "su faceta como ingrediente casi exclusivo en las expresiones de escaso contenido intelectual, propias de clases menos instruidas, para pasar a representar el lugar habitual de las manifestaciones de los más diversos grupos sociales." Hecho este que, además del factor ceremonial y protocolario, justifica su interés académico.

Trigueros, un municipio de Huelva de unos 7.000 habitantes, protagoniza cada año una de las fiestas más singulares de Andalucía que aúna precisamente el componente religioso con un destacado trasfondo civil y arraigo popular. Como en otras festividades cívico-religiosas en Andalucía, procesionan juntas autoridades civiles y religiosas representantes de la población, con un orden establecido desde hace años a través de la costumbre.

En este contexto, cabe destacar además que, a pesar de la relevancia popular e histórica de esta festividad, no existen referencias académicas de rigor que analicen esta celebración popular, civil y religiosa.

\subsection{Objetivos del trabajo}

El objetivo principal de este trabajo es profundizar en el estudio de las fiestas de San Antonio Abad desde el punto de vista de la organización de actos, el ceremonial y el protocolo, considerando la importancia que el ceremonial tiene en la conservación de elementos festivos tradicionales que conforman la cultura popular de nuestro entorno, en concreto de la localidad de Trigueros, Huelva. Para poder cumplir con el objetivo principal propuesto, es necesario el cumplimiento consecutivo de los siguientes objetivos secundarios:

OS1: Crear un marco teórico sólido en torno a la organización de actos, el ceremonial y el protocolo en relación a la organización de fiestas populares en las entidades locales.

OS2: Realizar un breve acercamiento histórico y ceremonial a las fiestas de San Antonio Abad celebradas en la localidad de Trigueros (Huelva).

OS3: Determinar la existencia, y en su caso, analizar la normativa legal existente en torno a la organización de las fiestas objeto de estudio.

OS4: En dependencia del objetivo secundario anterior, realizar una propuesta de reglamento municipal para regular, sistematizar y conservar el desarrollo de la festividad, en concreto en relación a la ordenación de las autoridades civiles y religiosas en las dos procesiones principales: Traslado y Procesión de Tercia.

\subsection{Hipótesis}

Se tiene sospecha que las Fiestas de San Antonio Abad se empezaron a celebrar sobre el siglo XVIII, sin embargo, no se tiene constancia de las mismas hasta el siglo XIX. Se puede afirmar que estas festividades gozan de una gran tradición histórica popular en la localidad de Trigueros (Huelva) que trasciende de la propia provincia. 
En este sentido, aunque la administración local y sus autoridades participan activamente en la organización y desarrollo de las fiestas objeto de estudio (convirtiéndola en una de las más emblemáticas de la zona geográfica), parece no existir, tal y como sucede con otras celebraciones civiles / religiosas del ámbito municipal, un reglamento o normativa local que la regule y permita preservar su esencia tradicional.

\section{METODOLOGÍA}

Para cumplir con el desarrollo de los objetivos planteados, se plantea un diseño metodológico sustentado en el concepto de la triangulación metodológica propugnado inicialmente por Denzin $(1970,1975,1989)$ puesto que se combinan de forma complementaria técnicas cualitativas y técnicas cuantitativas para optimizar la obtención de datos y la eficacia de los resultados.

De esta forma, el diseño metodológico del presente trabajo pivota entre el análisis de contenido, el análisis de documentos (audiovisuales y legales) y la entrevista en profundidad a observadores expertos (Corbetta, 2010: 358).

\subsection{Aplicación del análisis de contenido}

Para Walizer y Weinir (1978) el análisis de contenido implica la aplicación de un procedimiento sistemático ideado para examinar el contenido de una información previamente archivada. En este sentido, Kerlinger (1986) sostiene que el análisis e contenido es un método de estudio y análisis de comunicación de forma sistemática, objetiva y cuantitativa, cuya finalidad se orienta necesariamente hacia la medición de determinadas variables previamente identificadas en la formulación de la cuestión investigable objeto de estudio.

Para Piñuel Raigada (1995: 511):

Se llama actualmente análisis de contenido al conjunto de procedimientos interpretativos y de técnicas de comprobación y verificación de hipótesis aplicadas a productos comunicativos (mensajes, textos y discursos) o a interacciones comunicativas, que, previamente registradas, constituyen un documento con el objetivo de extraer y procesar datos relevantes sobre las condiciones mismas en que se han producido, o sobre las condiciones que puedan darse para su empleo

\section{posterior.}

Bajo estos enfoques, se realiza una ficha de medición y comparación de variables vinculadas a la organización ceremonial de la fiesta objeto de estudio, fundamentalmente en relación con:

- la secuencia de la fiesta,

- la concurrencia de autoridades civiles y religiosas y 
- la trayectoria histórica.

La ficha se aplica sobre el cuerpo de análisis conformado por los Programas de las Fiestas de San Antonio Abad existentes entre 1915 y 2018. Para acceder a estos documentos se realiza una búsqueda sistemática en dos fases:

10: Búsqueda de cada uno de los documentos en el Archivo Municipal (el primero del que existe registro oficial data de 1915) y, en el caso en que dicho Archivo no posea el programa que se necesita,

2o Búsqueda en distintos archivos privados y familiares de la localidad.

30 Aplicación de la ficha de análisis sustentada en los siguientes datos:

- Año

- Simbología visual contexto (banderas, escudos, etc.)

- Formato del programa (tipografía, etc.)

- Mensajes institucionales que aparecen en el programa

- Secuencia de la fiesta

- Datos sobre la asistencia de autoridades

- Observaciones

\subsection{Análisis de documentos audiovisuales}

Además de los programas de las fiestas, se analizarán los vídeos conservados por la televisión local de Trigueros de las dos procesiones de dichos festejos donde concurren autoridades y personalidades civiles, militares, judiciales y eclesiásticas: Procesión de Tercia y Traslado. Para Corbetta, el uso de documentos procedentes de medios de comunicación constituye una interesante técnica de investigación cualitativa de recolección de datos (2010: 390), en este sentido, se analizarán los videos correspondientes a los años 1988, 1997 y 2017 para recabar datos, desde una perspectiva diacrónica, acerca de la trayectoria y evolución de la ceremonia analizada.

\subsection{Análisis de documentos legales}

Se analizan normativas locales de referencia en la materia, así como:

- Decreto 77/2002, de 26 de febrero, por el que se regula el régimen de precedencias y tratamientos en el ámbito de la Junta de Andalucía.

- Cortejo de la Procesión del Corpus Christi de Sevilla, del año 2010. 


\subsection{Entrevista a observadores expertos}

Asimismo, para la realización de esta investigación se ha contactado con la persona responsable de la gestión del Archivo Municipal de Trigueros, el Secretario del Excmo. Ayuntamiento de Trigueros, el Párroco Párroco de la localidad y se realiza una entrevista personal a un observador experto anónimo de la localidad que conserva uno de los archivos privados más completos que existen en la actualidad.

\section{EL SERVICIO DE PROTOCOLO EN LAS INSTITUCIONES LOCALES}

Todas las administraciones, nacionales, autonómicas o locales, necesitan departamentos de comunicación y relaciones públicas para gestionar las relaciones con sus públicos de interés. Dentro de este ámbito, la organización de actos, a través del ceremonial y el protocolo, se vislumbra como una técnica genuina de relaciones públicas (Pulido, 2016) que facilita la transmisión de mensajes corporativos e institucionales a sus stakeholders. Como menciona Quintas (2005: 667)., "las entidades locales como los ayuntamientos son los responsables de iniciar y mantener un proceso de comunicación con sus públicos en el que el protocolo juega un papel importante que, desafortunadamente, pasa desapercibido".

Para Marín Calahorro (2000: 33) el protocolo constituye una herramienta para la ordenación de actos en corporaciones locales forma parte de la comunicación institucional porque:

- "Todo ceremonial constituye una pauta para la puesta en escena de interacciones comunicativas revestidas de rango social.

- En la actividad social de instituciones/corporaciones y organizaciones, son imprescindibles determinadas interacciones comunicativas, que requieren una cuidada escenificación para conseguir reconocimiento social".

Por tanto, es imprescindible una jefatura de protocolo en cualquier entidad local, como bien afirma (Quintas, 2005: 672):

Teóricamente, la Jefatura de Protocolo y Ceremonial, debe existir en todas las corporaciones del Estado - autonómicas y locales - así como en todas aquellas en que, por tradición o por sus especiales circunstancias representativas o turísticas, sea conveniente. Un Ayuntamiento debería incorporar este Servicio a su estructura orgánica para ayudar a cumplir sus objetivos sociales, generando además una buena imagen institucional. Hoy en día no todas las Corporaciones locales son conscientes de la necesidad

de incluir en su organigrama un Servicio de Protocolo, quizá por desconocimiento o ignorancia de sus funciones.

Según López-Nieto (2007:269), el protocolo es importante en la vida local porque: 
- Permite conservar aquellas costumbres más arraigadas en la sociedad y que generalmente aparecen siempre vinculadas a la vida local y,

- Al estar más cerca del ciudadano, facilita su incursión en la vida colectiva cuando participa en los actos oficiales locales

En este contexto, Fuente (2004: 456) establece un ordenamiento básico de las corporaciones municipales, basado en la práctica generalizada que atiende a la siguiente estructuración:

1. Alcalde.

2. Tenientes de Alcalde, por su orden.

3. Portavoces de los grupos municipales de mayor a menor, según resultados electorales.

4. Concejales de los grupos municipales de mayor a menor, según resultados electorales.

5. Secretario General.

6. Interventor.

7. Tesorero.

8. Oficial Mayor.

9. Jefe de la Policía Local.

\subsection{Los actos cívico-religiosos en las entidades locales}

Como se ha mencionado anteriormente, los ayuntamientos son las instituciones oficiales que más actos celebran. De ellos, los actos cívico-religiosos forman buena parte de la vida local, entre los que podemos destacar las fiestas patronales y las procesiones.

Según López-Nieto (2007: 275):

Las fiestas patronales suelen tener más importancia en los municipios que en las provincias y su duración alcanza varios días. Aquí la tradición cobra toda su importancia, por lo que no puede hablarse de un tipo de fiesta, sino que cada localidad celebra con arreglo a sus costumbres

estas fiestas, en la que se descubren una serie de actos, a los que se aplicarán las normas de protocolo que exija su propia naturaleza.

Por otro lado, las procesiones son un poco más complejas, ya que la Iglesia tiene sus propias normas de ceremonial, por lo que el poder civil y el eclesiástico tienen que organizar juntos este tipo de celebraciones. Además, como muy bien apunta López-Nieto (2007: 275): 
(...) habrá que contactar con las entidades religiosas que puedan tomar parte activa en la organización, como pueden ser las cofradías, hermandades, etc. De todo ello dependerá, además, la determinación de la comitiva en que toda procesión consiste, que variará también según la importancia eclesiástica del lugar en que se celebre (sede episcopal, parroquial, etc.).

En este sentido, para Díaz (2002:173), las procesiones se clasifican en ordinarias y extraordinarias:

- Ordinarias. Aquéllas que se realizan en días determinados siguiendo lo prescrito por la normativa o la costumbre. Se pueden citar: Presentación del Señor, Domingo de Ramos, Pasión, Vigilia Pascual y Santísimo Sacramento.

- Extraordinarias. Son ordenadas por la Conferencia Episcopal, en el caso de rogativas. Respecto al ordinario del lugar, se organizan ante un caso de necesidad pública o cuando se celebran con la presencia de reliquias e imágenes. El orden a seguir en estas procesiones varía según el tipo de celebración.

Aun así, López-Nieto establece las bases de un régimen de precedencias de autoridades y símbolos civiles y eclesiásticos dentro de las procesiones que tienen lugar en los municipios españoles y en los que participa la Corporación Local. El orden en una procesión sería el siguiente (2007:276):

1. Cruz.

2. Miembros de entidades religiosas.

3. Colegios profesionales (si los hubiese).

4. Diputación provincial o Cabildo insular (si los hubiese) en Corporación.

5. Ayuntamiento en Corporación.

6. Clero parroquial y órdenes religiosas.

7. Párroco.

8. Banda municipal de música.

9. Policía local.

Hay que tener en cuenta que "en las procesiones religiosas la precedencia en cargos eclesiásticos corresponde a la persona que camina en último lugar, y el último rango al que va el primero" (Escalera, 2005:82). Es por ello por lo que en el régimen de precedencias básico creado por López-Nieto observamos que el párroco va en último lugar, a lo que autoridades eclesiásticas se refiere. El problema de todo ello radica en que "las procesiones y solemnidades religiosas que se celebren en honor de los santos patronos o vírgenes no son consideradas actos oficiales. Tampoco lo son aquellos eventos tradicionales de carácter 
religioso o popular a los que concurren autoridades civiles por invitación de los organizadores" (Escalera, 2005:82).

Se podría pensar que este estudio no tendría sentido, ya que, como muy bien afirma Escalera, las procesiones no son consideradas actos oficiales. Sin embargo, los actos que se procede a analizar se enmarcan dentro de las fiestas patronales de Trigueros, y es el propio ayuntamiento de la localidad el que las organiza, aunque tengan, en parte, un contenido religioso.

\section{RESULTADOS}

A continuación, se muestra el esquema básico que subyace al periodo analizado en cada una de las ceremonias analizadas. Evidentemente existen breves y pequeñas alteraciones a lo largo de los años que, por la extensión de este trabajo, no pueden ser mostradas en su totalidad.

\subsection{El traslado}

El orden de precedencias en el traslado de la imagen del patrón de su ermita a la iglesia parroquial es el siguiente:

Primer recorrido: las autoridades van a buscar a la iglesia al párroco, para ir juntos a abrir la puerta de la ermita para que los fieles lleven a su patrón a la iglesia.

1. Banda Municipal de Música.

2. Cruz parroquial.

3. Bandera de España.

4. Policía Local.

5. Párroco y Alcalde (a la misma altura, de derecha a izquierda).

6. Juez de Paz.

7. Guardia Civil.

Una vez que se abre la puerta de la ermita, a esta comitiva se le añaden representantes de las diferentes Hermandades de Gloria y/o de Penitencia. Dichas Hermandades se ordenaban por antigüedad en este año; las de menos antigüedad iban las primeras, y por tanto, más alejadas de la imagen de San Antonio Abad, y las más antiguas, más cercanas al patrón. Por tanto, el orden del segundo recorrido sería el siguiente:

1. Cruz Parroquial.

2. Asociación Parroquial Cruz de Pedrancha.

3. Hermandad de San José Obrero. 
4. Hermandad de la Inmaculada Concepción.

5. Hermandad de la Virgen de Fátima.

6. Hermandad de la Virgen del Rocío.

7. Hermandad de la Virgen del Carmen.

8. Hermandad de Jesús y María.

9. Hermandad del Santo Entierro.

10. Consejo Parroquial.

11. Bandera de España.

12. Corporación Municipal.

13. Policía Local.

14. Párroco y Alcalde (en orden de derecha a izquierda).

15. Juez de Paz.

16. Guardia Civil.

17. Capataz.

18. Imagen de San Antonio Abad.

19. Banda Municipal de Música.

Los fieles que van acompañando al patrón en dicha procesión se sitúan detrás de la imagen de este, y delante de la Banda Municipal de Música.

\subsection{La Procesión de Tercia}

Por su parte, en la Procesión de Tercia, que tiene lugar el domingo por la mañana, el orden de precedencias es muy parecido al del Traslado del sábado. Sin embargo, se dan algunos cambios:

1. Banda de Cornetas y Tambores.

2. Cruz Parroquial.

3. Asociación Parroquial Cruz de Pedrancha.

4. Hermandad de San José Obrero.

5. Hermandad de la Inmaculada Concepción.

6. Hermandad de la Virgen de Fátima. 
7. Hermandad de la Virgen del Rocío.

8. Hermandad de la Virgen del Carmen.

9. Hermandad de Jesús y María.

10. Hermandad del Santo Entierro.

11. Consejo Parroquial.

12. Capataz.

13. Imagen de San Antonio Abad.

14. Sacerdotes y Párroco (este último va en el centro).

15. Bandera de España.

16. Guardia Civil y Juez de Paz (este último va en el centro).

17. Alcalde y Corporación Municipal (en el centro se sitúa el Alcalde).

18. Banda Municipal de Música.

La Banda de Cornetas y Tambores no es usual en estas celebraciones. Pero, se observa, cuando confluyen dos bandas de música, una se sitúa al principio de la procesión, delante de la cruz parroquial, y la otra ocupa el último lugar de la comitiva.

Se procede al análisis de las dos procesiones en el año 1997 en el que, con respecto a la década anterior, se dan algunos cambios. Traslado del sábado:

Primer recorrido, en el que las autoridades civiles van a buscar a las autoridades eclesiásticas, para ir a la ermita de San Antonio Abad:

1. Bandera de España.

2. Presidente de la Asociación Civil San Antonio Abad, Alcalde y Capataz (en la misma línea, de derecha a izquierda).

3. Corporación Municipal.

4. Juez de Paz.

5. Policía Local.

6. Banda Municipal de Música.

Una vez que sale la imagen del patrón de la ermita, el orden de precedencias es:

1. Cruz Parroquial.

2. Asociación Parroquial Cruz de Pedrancha. 
3. Hermandad de San José Obrero.

4. Hermandad de la Virgen de Fátima.

5. Hermandad de la Virgen del Rocío.

6. Hermandad de la Virgen del Carmen.

7. Hermandad del Santo Entierro.

8. Grupo Scout.

9. Hermandad de Jesús y María.

10. Párroco, Cuerpo de Acólitos y otras autoridades eclesiásticas (se ordenan entre ellas, siguiendo la regla: el rango más alto se sitúa en el centro y los siguientes se sitúan de derecha a izquierda con respecto al centro, en función del rango e importancia).

11. Juez de Paz.

12. Bandera de España.

13. Corporación Municipal.

14. Policía Local.

15. Presidente de la Asociación Civil San Antonio Abad, Alcalde y Capataz (en la misma línea, de derecha a izquierda).

16. Imagen San Antonio Abad.

17. Banda Municipal de Música.

Se observa que, con respecto al año anterior, se dan algunos cambios: la Hermandad de la Inmaculada Concepción ya no existe, por eso no sale su Simpecado en procesión; se ha incluido una representación del Grupo Scout, que no debería ocupar ese lugar, pero lo hace por tratarse de un grupo de jóvenes vinculados a la Hermandad de Penitencia de Jesús y María.

También podemos observar que ya el párroco y el alcalde no van en la misma posición. Por tanto, los diferentes poderes y estamentos se van separando.

Por su parte, en la procesión de Tercia, el orden es prácticamente el mismo, dándose los siguientes cambios:

1. Cruz Parroquial.

2. Asociación Parroquial Cruz de Pedrancha.

3. Hermandad de San José Obrero. 
4. Hermandad de la Virgen de Fátima.

5. Hermandad de la Virgen del Rocío.

6. Hermandad de la Virgen del Carmen.

7. Hermandad del Santo Entierro.

8. Grupo Scout.

9. Hermandad de Jesús y María.

10. Cuerpo de Acólitos.

11. Bandera de España.

12. Juez de Paz y Corporación Municipal (sin orden establecido).

13. Párroco.

14. Presidente de la Asociación Civil San Antonio Abad, Alcalde y Capataz (en la misma línea, de derecha a izquierda).

15. Imagen San Antonio Abad.

16. Banda Municipal de Música.

Como se puede observar, lo más llamativo es que el Párroco se mezcla aquí con la Corporación Municipal y el Alcalde, dejando en otra posición al Cuerpo de Acólitos.

Ya en el año 2017, el orden de precedencias del Traslado del sábado es el mismo que para la Procesión de Tercia del domingo. Se va a ahondar un poco más en intentar definir mejor los cargos de dentro de cada Hermandad:

1. Escuela de tamborileros.

2. Cruz Parroquial.

3. Hermandad de San José Obrero. Tres filas:

a. Cuatro personas de la junta directiva de la Hermandad. En el centro se sitúan la Hermana Mayor y la Presidenta, de derecha a izquierda.

b. Cuatro personas de la junta directiva de la Hermandad.

c. Estandarte de San José Obrero.

4. Hermandad de la Virgen de Fátima. Dos filas:

a. Tres miembros de la junta. Es difícil definir el cargo de cada una de ellas, ya que en esta Hermandad, los miembros de la junta se turnan para salir en cada procesión, por lo que de una a otra no se repite. 
b. Simpecado de la Virgen de Fátima.

5. Hermandad de la Virgen del Rocío. Cuatro filas:

a. Próximos/as Hermanos/as Mayores: (de derecha a izquierda) Hermana Mayor entrante y Hermana Mayor dentro de dos años.

b. En el centro se coloca el Presidente de la Hermandad. A su derecha la Hermana Mayor; y a su izquierda puede ir el Vicepresidente, el Secretario o el Tesorero de la Hermandad (se turnan en cada procesión).

c. Simpecado de la Virgen del Rocío.

d. Miembros de la Junta Directiva de la Hermandad (sin orden aparente entre ellos).

6. Hermandad de la Virgen del Carmen. Dos filas:

a. La Presidenta de la Hermandad se sitúa en la posición central, y tanto a su derecha, como a su izquierda se colocan dos miembros de la Junta Directiva.

b. Simpecado de la Virgen del Carmen.

7. Hermandad del Santo Entierro. Tres filas:

a. El estandarte de la Hermandad se sitúa en medio. A su derecha, se coloca un miembro de la Junta Directiva de la Hermandad (Vicepresidente, Secretario o Tesorero); y a la izquierda el Presidente.

b. En los extremos se colocan dos miembros de la Junta Directiva.

c. En los extremos se colocan dos miembros de la Junta Directiva.

8. Hermandad de Jesús y María (Hermandad Sacramental). Tres filas:

a. Estandarte de la Hermandad.

b. Tres miembros de la Junta Directiva.

c. El Presidente se coloca en el lugar central, mientras que dos miembros de la Junta Directiva se sitúan a su derecha e izquierda.

9. Cuerpo de Acólitos. Dos filas (dependerá del momento, y de las personas que en ese momento formen parte del Cuerpo).

a. Tres monaguillos.

b. Dos monaguillos. 
10. Asociación Civil San Antonio Abad. En una misma fila se colocan dos representantes de la asociación. Sin embargo, puede darse el caso de que haya hasta seis personas, lo que haría que se colocaran en dos filas de a tres.

11. Jueza de Paz. A su derecha se sitúa el Cabo de la Policía Municipal de Trigueros; y a su izquierda el Comandante de Puesto de la Guardia Civil.

12. Bandera de Trigueros.

13. Corporación Municipal. Los primeros lugares los ocupan los miembros de la oposición, de menor a mayor representación política. Detrás de ellos, se coloca el Equipo de Gobierno.

14. Alcalde. A su derecha se sitúa el Presidente de la Asociación Civil San Antonio Abad; y a su izquierda el Capataz del paso de San Antonio Abad.

15. A la derecha se sitúa el Diácono, y a la izquierda el Párroco Párroco.

16. Imagen de San Antonio Abad.

17. Asociación Músico-Cultural José del Toro. Se colocan en filas de cuatro músicos. Los instrumentos van situados de sonidos más graves a agudos, con la percusión encabezando la marcha.

\section{CONCLUSIONES}

Las fiestas populares suelen tener un importante arraigo histórico que deriva en cultura e identidad de la población en la que se inserta, organiza y desarrolla, erigiéndose como verdaderas herencias culturales que proporcionan una caracterización propia y original a la localidad.

Esta herencia cultural, se manifiesta y se ancla en el inconsciente colectivo gracias al desarrollo de las ceremonias, ritos y procesiones (en el caso de las celebraciones cívicoreligiosas) de las que suelen ir acompañadas. En este sentido, la organización de actos vuelve a mostrarse, a través del ceremonial y el protocolo, como una poderosa herramienta de gestión de las relaciones institucionales capaz de transmitir valores identitarios que proporcionan sentimientos de adhesión, querencia histórica y fervor popular.

Bajo este enfoque, este trabajo demuestra principalmente que:

- Esta singular fiesta nunca se ha dejado de celebrarse a lo largo del siglo XX y XXI. Ni siquiera durante la II República, ni durante los años que duró la Guerra Civil.

- No consta ningún tipo de manual, ni de reglamento oficial que regule el orden de precedencias en las procesiones de las fiestas en honor a San Antonio Abad que permita preservar su esencia histórica.

- Como se ha podido observar, los cambios en el lugar que ocupan las autoridades, tanto civiles, como eclesiásticas, no han sufrido demasiados cambios con respecto al paso 
de los años. Aunque si bien se asiste a la desaparición de algunas hermandades y/o asociaciones, como, por ejemplo, la de la Inmaculada Concepción, o la Asociación Parroquial Cruz de Pedrancha.

- Se puede afirmar que el criterio por el que se ordenan las Hermandades es el orden de antigüedad (la más antigua va más cerca del paso de San Antonio Abad), teniendo preferencia, siempre, la Hermandad (o Hermandades) Sacramental(es). En la actualidad, solo hay una: la Hermandad de Penitencia de Jesús y María, que se coloca en la última posición del cortejo de hermandades.

- Es posible sistematizar las secuencias básicas de sus ceremonias principales.

\section{REFERENCIAS BIBLIOGÁFICAS}

Arias Valencia, M. M. (2000): La triangulación metodológica: sus principios alcances y limitaciones. https://www.uv.mx/mie/files/2012/10/Triangulacionmetodologica.pdf

Cabrero Soto, C. (2012). Gestión de protocolo. Madrid, España: Ediciones Paraninfo.

Carrasco Terriza, M.J. (2012): Hermandad de San Antonio Abad de Trigueros 1706. Fiestas de San Antonio Abad. Trigueros: . Ayuntamiento de Trigueros

De Urbina, J.A. (2005): El gran libro del protocolo. Madrid, España: Temas de Hoy.

Denzin, N. K. (1970). The research act. Chicago: Aldine Publishing. Denzin, N. K. (1975). The research act. A theoretical introduction to sociological methods. New York: McGraw Hill.

Denzin N. K. (1989). Strategies of Multiple Triangulation. The Research Act: A theoretical Introduction to Sociological Methods. New York: McGraw Hill.

Díaz Bonilla, M.A. (2002): Organización, ceremonial y protocolo en la Iglesia Católica. Madrid, España: Ediciones Protocolo.

Escalera Aicua, S. (2005): Ceremonial y protocolo religioso. Madrid, España: Ediciones Protocolo.

Fuente Lafuente, C. (2004): Protocolo Oficial. Las instituciones españolas del Estado y su ceremonial. Madrid, España: Ediciones Protocolo.

García Martín, M.J. (2008): Los Repiques y las Fiestas del Santo. Nuestras Campanas, todo un símbolo de la vida cotidiana y de los avatares históricos de Trigueros. Fiestas de San Antonio Abad. Trigueros: Ayuntamiento de Trigueros.

López-Nieto, F. (2007): Manual de protocolo. Barcelona, España: Ariel.

Marín Calahorro, F. (2000): Protocolo y comunicación. Barcelona, España: Editorial Bayer Hnos.

Moreno Navarro, I. (1997). Los rituales festivos religiosos andaluces en la contemporaneidad. $1^{\mathrm{a}}$ jornada de Religiosidad Popular. Almería. (Visto en: https://idus.us.es/xmlui/handle/11441/17858). 
Otero Alvarado, M.T. (2011): Protocolo y empresa. El ceremonial corporativo. Barcelona, España: Editorial UOC.

Pulido Polo, M. (2016). Manual de organización de actos oficiales y empresariales. Madrid, España: Síntesis.

Quintas Froufe, N. (2005). Protocolo local: una necesidad. Tendencias actuales en las relaciones públicas: II Congreso Internacional de Investigadores en Relaciones Públicas. Facultad de Comunicación de la Universidad de Sevilla. (Visto en: https://idus.us.es/xmlui/handle/11441/39278).

Ruiz Acosta, M.J. (2002). Religiosidad popular y comunicación en Andalucía. En Hurtado Sánchez, J. (Ed.), Nuevos aspectos de la religiosidad sevillana. Fiesta, Imagen, Sociedad. Sevilla, España: Ayuntamiento de Sevilla (Servicio de Publicaciones).

Sánchez González, D.M. (2011): Fundamentos del ceremonial y del protocolo. Madrid, España: Síntesis. 
